\section{Questión}

Periodismo / Comunicación ISSN 1669-6581
- Av. $44 \mathrm{~N}^{\circ} 676,1^{\circ}$ piso

CP 1900 - La Plata - Argentina

www.perio.unlp.edu.ar/question

Interrogantes en tiempos de educación virtual

Gustavo Cimadevilla

DOI: https://doi.org/10.24215/16696581e281

\title{
Interrogantes en tiempos de educación virtual
}

\section{Questions in times of virtual education}

Gustavo Cimadevilla / gcimadevilla@yahoo.com.ar Profesor Titular del Departamento de Ciencias de la Comunicación, Facultad de Ciencias Humanas, UNRC. Director del Doctorado en Ciencias Sociales. Presidente de la Asociación Latinoamericana de Investigadores de la Comunicación, ALAIC. i

Como una tromba viral, la pandemia del COVID-19 irrumpió en la vida diaria de los mortales, cualquiera sea el sitio en el que viviesen, alterando sus rutinas y provocando que diversas políticas sanitarias se activen para hacer frente al mal. La clausura de actividades y el confinamiento marcan esta época de incertezas, malas noticias y angustia generalizada.

El "Quédate en casa" fue y es más que un slogan, también es una consigna que ilustra el paisaje de los escasos movimientos, la economía jaqueada por la falta de producción, consumo y circulación, las tareas en el hogar y la interminable reinvención de lo cotidiano, en donde la creatividad muestra cuánto el humano puede hacer si de amenazas a su integridad se trata.

La educación, en tanto, que se dinamiza fundamentalmente a través del trabajo en aula y espacios de presencialidad, fue una de las primeras en recibir el impacto. Desde su inicio se cancelaron cursos, agendas académicas y cerraron incluso las instituciones, resguardándose algunas instancias mínimas para repensar el quehacer formativo. En las universidades en particular, dado que en Argentina rige la "autonomía" para sus normativas y decisiones de gestión académica y administrativa -con diferencias para las públicas y las privadas-, el panorama parece ser bastante variopinto y los cronogramas muy particulares.

Como mencionara recientemente en otro diálogo (Cuadernos de Humanidades, UNSalta), el sistema universitario argentino, a diferencia por ejemplo del brasileño, que es totalmente 
dependiente de su ministerio de educación, es altamente autoadministrado y como aquí la descentralización universitaria tiene más historia y políticas que la avalan, eso repercute en las dinámicas que cada universidad adopta. Por cierto, muy distintas: UBA, por ejemplo, replanteó su cronograma académico a partir de junio y con las modalidades ya vigentes; en tanto otras universidades buscaron alternativas de reprogramación mixtas, en donde mantuvieron los calendarios incluyendo la modalidad virtual. Algunas están totalmente cerradas, de barreras bajas, y otras manteniendo alguna posibilidad de contacto en las infraestructuras. Los gremios, por su parte, presentaron diversas posiciones. En Río Cuarto, por ejemplo, el correspondiente a los No Docentes ha sido muy crítico con el teletrabajo y manifestó su total oposición.

La eduvirtualidad, mientras tanto, se impuso en muchas de las unidades académicas. Con pocas excepciones, desde la primaria hasta la universidad, pasando por muchas otras alternativas de instancias formativas, lo virtual copó la escena y una principal interrogación sobrevuela el ambiente: ¿Cómo lo hacemos? ¿Cómo se hace? ¿Tiene sentido hacerlo?

Por el momento es difícil evaluar ese escenario tan variado, pero se podría decir, en virtud de la información que circula, que los intentos de virtualización de la educación en las instituciones públicas -quizás las privadas tengan mayor experiencia- se caracterizan por la heterogeneidad, cierta magnificación en las expectativas, baja presencia de diagnósticos que muestren las condiciones en las que operan las conexiones, emisiones y participaciones, y una latente necesidad de evaluar todas esas experiencias. Si la presunción es válida, se pueden generar falsos pronósticos, avales apresurados y merituaciones que habiliten a ciertos estudiantes y desconozcan que otros ni siquiera se enteraron de que las carreras continúan dictando sus clases u otras variantes por el estilo.

Claro que resulta loable que desde cada institución se piense qué hacer frente a esta coyuntura y se implementen salidas, puesto que de lo contrario diríamos que hemos sido abandonados. Por otro lado, visto desde su conjunto, autoridades, nosotros los educadores y los no docentes, somos todos servidores del estado que mes a mes recibimos compensas salariales por hacerlo y corresponde por tanto cumplir efectivamente con ese contrato laboral y social, ya que los recursos que se aplican son de todos los que pagan y pagamos los impuestos.

Ahora, en ese qué hacer desde la institución y ciertas preocupaciones vigentes, vale anotar: 1. Una ansiedad recurrente por los resultados, en un marco donde las experiencias son tan disímiles que buscar regularidades por ahora es una tarea en agenda. 2. Cierta lectura 0 
imaginario respecto de qué tipo de docentes somos y qué tipo de alumnos tenemos. En general, un poco idealizados desde el vamos. Por ejemplo, porque para ambas categorías se estima que todos están dispuestos a educar y educarse bajo esta modalidad. Que todos/as tienen los medios para hacerlo, mínimamente, y que resulta posible efectuarlo de manera más o menos similar, en lo que respecta a los posibles resultados a obtener, de lo que ocurre de manera presencial.

De ese modo, las preguntas que desde la institución se elaboran y convidan a responder parecen más bien alimentar y reproducir ese imaginario inflacionado. Cuando en realidad las respuestas posibles a esta altura van a ser muchos más dubitativas, escasamente interesantes para concluir y poco efectivas si se quiere a partir de ellas planificar ciclos lectivos "normales". El cómo resuena en la comunidad educativa esa amalgama virtual es también un gran interrogante. Las universidades nacionales tienen más de 190 mil cargos docentes, con una mínima cantidad de dedicaciones exclusivas (11 ó 12 por ciento), de modo que todos aquellos que tienen prestaciones menores seguramente ven repartidas sus preocupaciones con otros trabajos y realidades y no está claro hasta qué punto pueden acompañar los procesos de virtualización puestos en marcha.

En las redes, además, se percibe que quienes están siguiendo y participando de esos procesos virtuales tienen muchas inquietudes sin resolver, advertencias respecto de las limitaciones que tienen estas experiencias de virtualización y mucha, mucha buena voluntad. Aunque no alcance. $Y$ no alcanza, porque entiendo que una de las debilidades claves de toda la experiencia es que debió ser improvisada.

Esto no significa que la educación virtual no permita redundar en éxitos de aprendizaje y de formación. De hecho, hay carreras organizadas por muchas instituciones, incluidas las nuestras, que lo contemplan. Pero una cosa es que una carrera o un trayecto de formación se origine y diseñe con esa modalidad $\mathrm{y}$, por tanto, se estructure y dinamice con pautas adecuadas para ello; y otra cosa es que en virtud de limitaciones tajantes como las que resultaron de la pandemia se busque que una carrera presencial pueda continuarse de modo virtual como si casi nada hubiese ocurrido.

$\mathrm{Ni}$ los docentes ni los alumnos acordaron desde un inicio hacerlo. La realidad permitió que se impusiera cierta política, y en esa imposición el círculo se generó defectuoso "por naturaleza", antes que virtuoso: porque las voluntades, las infraestructuras y condiciones -el estar 
preparado y dispuesto para- no estaban previstas, simplemente hubo que crearlas sobre la nada o sobre escasas experiencias alternativas. Se acudió entonces a la improvisación forzada.

Sin embargo, nos hemos formado y formamos para no improvisar, para no ser aleatorios y para no ser improvisados. Al borrar con el codo lo que aprendimos y siempre enseñamos, se produce una cierta incomodidad difícil de superar. ¿Hacemos ahora lo que siempre hemos criticado? ¿Nos sumamos a la profesionalidad del "después vemos"?

En otros trabajos (Cimadevilla, BCN Nro 123, 2007) nos hemos ocupado de mostrar ciertas falacias que suelen acompañar a lo virtual. Entre ellas, que: i) La existencia (tecnologías, infraestructuras, agentes, conocimientos) supone disponibilidad; ii) La disponibilidad conlleva al acceso; iii) El acceso/uso deriva en la resolución de problemas; iv) La resolución más efectiva se alcanza desde la virtualidad; y v) La virtualidad suplanta a la comunicación (en este caso diríamos presencial) y resulta equivalente. Cuando la realidad indica otra cosa.

Diversos motivos, contingencias, aleatoriedades y desigualdades permiten explicar por qué esa linealidad no se cumple, con lo cual toda expectativa por encima de las posibilidades reales parece sucumbir ante la propia experiencia.

Pero, si esto es así, ¿puede ser distinto? Podemos hoy, ya con el diario del lunes, ¿pensarlo de otra manera? ¿Podría ser esta experiencia realmente otra? ¿de qué dependería?

La presunción que quiero sostener es que una diferencia sustancial ante esta coyuntura hubiese sido la de modificar los términos del contrato educativo. Es decir, haber suspendido la formación presencial y todo lo que ello implica al generarse por canales de presencialidad, e inaugurar -con la pausa necesaria- una nueva instancia que sería únicamente virtual, pero nueva y específica. Invitar, por tanto, a adherir a un nuevo contrato formativo con determinadas condiciones y pautas, acotadas para un determinado período; por ejemplo, tres/seis meses o lo que hubiese sido razonable pensar y protocolizar con sus debidas limitaciones y proyecciones. De ese modo, con reglas claras de cursado desde un inicio y luego con reglas claras también de evaluación y legitimación de lo enseñado-aprendido, los imaginarios hubiesen sido otros, así como otras las expectativas de la formación.

Al no haberse realizado así, ahora nuestras instituciones que optaron por un enganche con lo virtual solicitan que se informe respecto de los posibles resultados obtenidos, como si las operaciones desde la cuasi normalidad permitiesen mensurar tan linealmente. Y allí me parece 
que opera un imaginario poco realista respecto de lo que está pasando y puede pasar en las redes y plataformas para ese fin dispuestas.

Primero, porque es poco lo que sabemos con cierta certeza respecto de lo que sucede en el campo educativo, y por tanto hay escasos datos para concluir que este régimen puede suplantar al otro con la debida integridad.

En un ejercicio de sondeo rápido llevado adelante en mi departamento académico -vía consulta por cuestionario autoadministrado por google- se obtuvieron aproximadamente un 75 $\%$ de respuestas de los estudiantes activos. De ellos, 6 de cada diez dijeron disponer de computador y acceso relativamente bueno a la red. El resto, advirtió diversas dificultades. Casi todos disponen de celular, pero no todos pueden con él suplir al computador. A la hora de evaluar esta experiencia de virtualidad, lo que han destacado como dificultades se vincula a la dispersión de recursos tecnológicos a los que deben ligarse (plataformas diversas y entornos heterogéneos) y la imposibilidad para una buena proporción de ellos/as de seguir clases on line.

Y si estas experiencias presentan esas dificultades y aún estamos lejos de mensurar debidamente los resultados, ¿qué es lo que se ofrece a quienes se adaptaron al nuevo marco? ¿La aprobación de los cursos, total o parcialmente? ¿La suposición de que los cursantes se han apropiado de los conocimientos, habilidades y experticias compartidas? ¿Y qué decir respecto de los que no han podido acompañar estas experiencias, se han retrasado en sus ciclos de formación y ello altera sus planes de graduación? ¿De qué manera pueden revertir o compensar esas faltas? ¿Con más virtualidad?

Preguntas claves cuyas respuestas demorarán en emerger y que parecen enseñarnos que muchas veces barajar y dar de nuevo es mucho más conveniente que emparchar. Sobre todo, cuando de la educación y profesionalidad se trata.

i El autor agradece a la Lic. Andrea Marina Datri por la lectura y comentarios efectuados a este texto. 